\title{
A Review of How Firms Strategically Lead by Innovating Technology Within the Sharing Economy - A Case of Opportunities, Disruptions, Criticisms and Regulations
}

\author{
Anietie G. Ukpabio \\ Doctoral Researcher of PhD in E-Research and \\ Technology Enhanced Learning Lancaster University. Lancaster, UK \\ Business Analyst at IBM Client Innovation Centre. Leicester, UK
}

\begin{abstract}
This article reviews how firms strategically lead by innovating technology within the sharing economy; highlighting the opportunities, disruptions, criticisms, and regulations associated with innovative technology. The article begins by defining sharing economy and its scale. Sharing economy is a complex phase with countless consequences that is adopted to define economic activities made possible through online transactions. To take a fair share of the market, companies use innovative technology. For example, eBay and Amazon utilize technologies such as Web 2.0 and mobile Apps to rid of market intermediaries, streamline transactions, and bring goods and services near people. Uber also allows customers to use a mobile application to reach drivers and this facilitates the sense of nearness. The use of technology in the sharing economy has many advantages. However, it carries with it some corrosive effects on the business community and society at large. Critics of technology are championing for stricter regulations. The sharing economy witnesses some pertinent disruptions caused by companies that innovate technology. They include unfair competition, lower entry barrier, regulations, quality standards, and financial sector risks.
\end{abstract}

Keywords: Sharing Economy, Sharing Platform, Mobile Application, Chicken and Egg Strategy, Porter's Five Forces, Force Field Analysis, Technology, e-Business

DOI: $10.7176 / \mathrm{EJBM} / 11-12-01$

Publication date: April $30^{\text {th }} 2019$

\section{Defining Sharing Economy \& Its Scale}

There is no boundary of the kind goods or services that can be shared in sharing economy. Although, the sharing economy is considered by some to consist of a range of services (Martin, 2016). Despite the existence of incongruence in its model and definition, this review adopts a much encompassing definition which originates from inferences gathered from the works of (Zervas et al., 2017): sharing economy is a comprehensive phrase with numerous implications, habitually adopted to define economic activities facilitated using online transactions. Initially pioneered out of the open-source community where access to goods and services are shared in a peer-topeer manner, there is also a broader implication of the phrase that connotes online market place transactions, including those that are of business to business (B2B) model (Zervas et al., 2017). Sharing economy platforms enable peers to swap, share, and rent and donate spare or available goods and services. Some notable services and firms are accommodation (like Airbnb, HomeAway), labour marketplaces (like Fiverr, TaskRabbit), transportation (like Uber, Lyft), open data services (like GitHub, London DataStore), just to mention a few. There are also other sharing economy related developments within the financial sector, like peer-to-peer lending and crowd-funding. Currently, according to (Sundararajan, 2016) the number of firms that dominate the sharing economy are reported to be over 30 with a yearly turnover of more than $£ 1.5 \mathrm{bn}$. With over 80 sharing economy start-ups reported to be located in London, the largest when compared with New York and San Francisco.

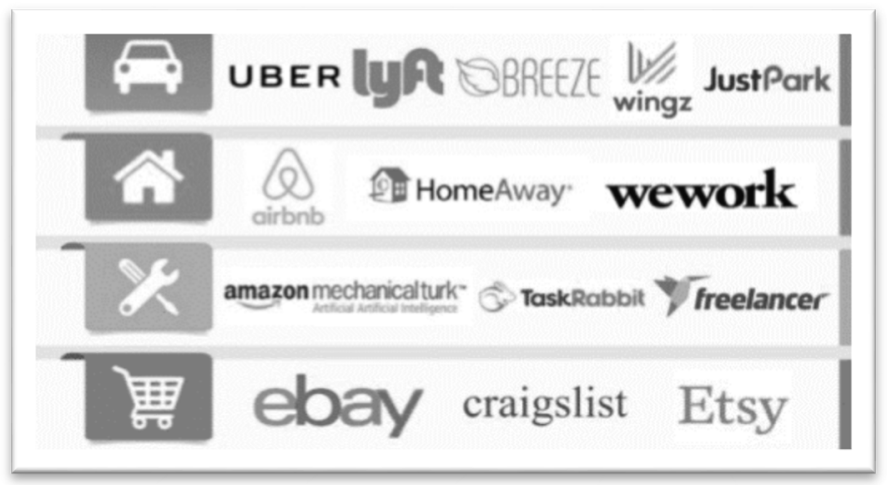

Figure 1.1: Some notable firms within sectors of the sharing economy 
Whilst considerably novel, the concept of sharing economy is presently an area of evolving advancement. There exist numerous implications of the concept, which makes it inherently difficult to approximate its scale, however, in the year 2013, the global consumer peer goods rental was guesstimated at $£ 23$ bn (Sundararajan, 2016). Another estimate about the rate of evolvement of the sharing economy means that $25 \%$ of adults that live in the UK used Internet technologies to share their spare assets and resources in the year 2013 (Cusumano, 2015).

Unsurprisingly, the works of (Dyal-Chand, 2015) highlighted that the governments, authorities, individuals and businesses of several nations are showing enormous interest in the sharing economy. Some of the themes which this interest oscillates are discussed in the subsequent sections of this review as regulatory developments.

\subsection{How Firms Use Technology to Take a Fair Share of the Market}

Evidentially, the degree of subscription by users to sharing platforms would indicate that there are substantial benefits derived from participation. Arguably, underpinning the inclination of users on sharing platforms is the evolvement and applicability of technology (like mobile apps and websites) by leading and innovation-focused firms (Möhlmann, 2015). As evidenced in some popular online marketplace (like EBay and Amazon), technologies like Web 2.0 and mobile applications can eliminate market intermediaries, flatten transactional processes and create a sense of nearness to the goods and services. Zervas et al. (2017) suggests that the technological implications go beyond corporate strategies towards economic strategies. At an economic level, the use of technology to enhance sharing can lead to an efficient distribution and utilisation of resources, thus improving economic productivity and efficiency. Even distribution of resources can reduce scarcity. This suggestion was further supported by Quattrone et al. (2017) by adding that the individual implication of using technology to enhance sharing spans into the reduction of economic costs to consumers by finding goods and services more effortlessly.

However, from a strategic standpoint, Cusumano (2015) argued that combining the platform and technology is not enough towards guaranteeing a firm's success in providing a sharing platform as a service. Along this line of thought, leading firms in sharing economy platforms have had to think critically about strategies that can help them penetrate the two-sided market mostly present on most sharing platforms (like Airbnb, Lyft, Uber, HomeAway, Fiverr, ZipCar). Notable among the problems they faced is that incessantly discussed by Lou and Koh (2018) and colloquially referred to as the chicken and egg problem; one used to describe the imbalance when the service's value proposition to the customers and the suppliers heavily depend on the penetration on the other. There is often a question about which side deserves more enticement and in which order the enticement should be introduced.

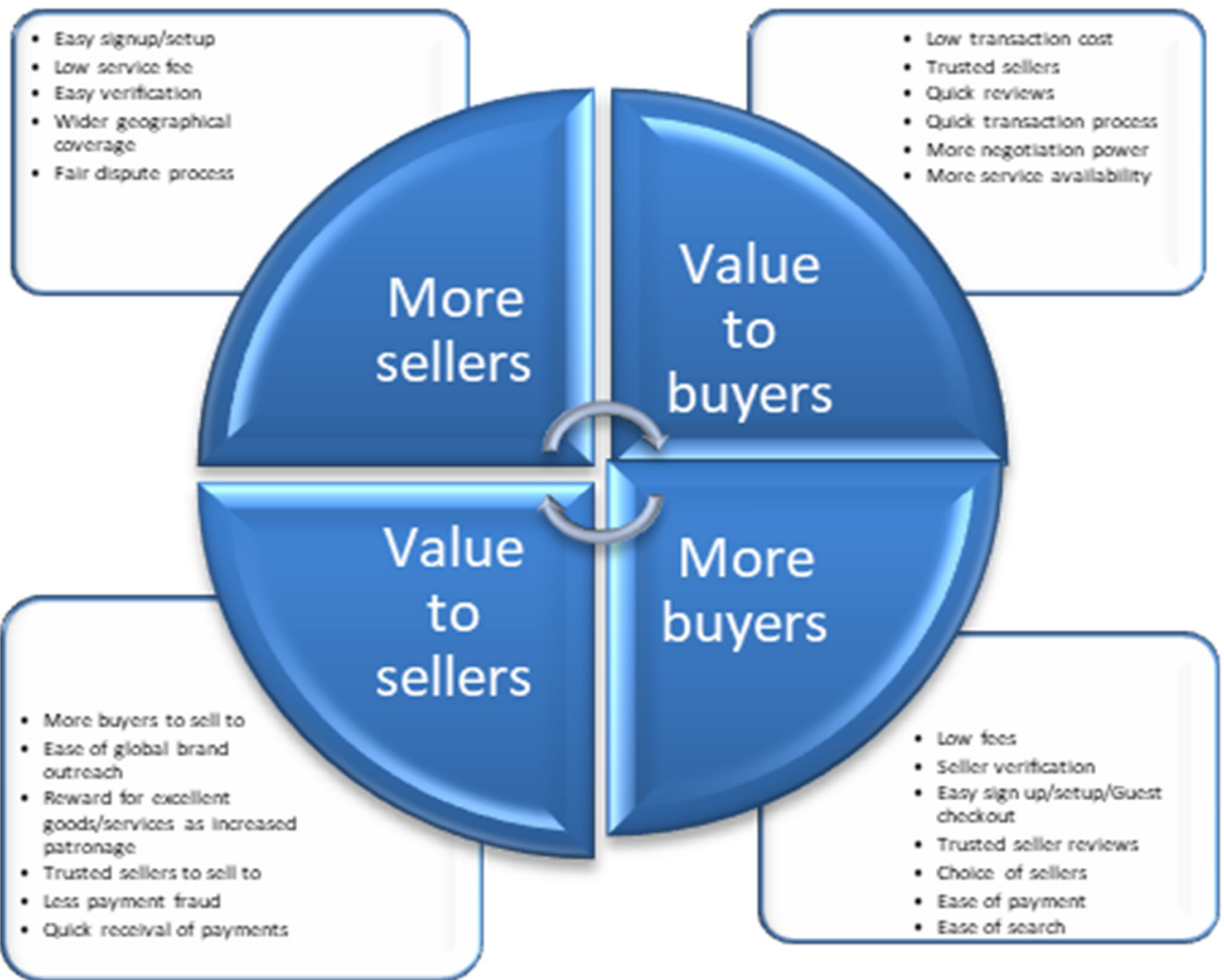

Figure 2.1: How firms use technology to mitigate the two-sided market (chicken and egg) problem. Based on the above diagram, there is a tendency to assume the network effect strategy solves the two-sided 
market problem without further interventions, nevertheless, Matzler et al. (2015) revealed that when sharing platforms are scoped from the lenses of Lewin (1943) force field analysis, new considerations may emerge that may force firms (like the case of Lyft and Uber or HomeAway and Airbnb) to rekindle their corporate strategic stance towards embracing various practicalities regarding the developments in social changes. Some of the changes are how the property owners want to share their properties, how property seekers would prefer to seek or prefer the property to be shared, new norms of sharing, agreed boundaries of sharing, other changes that may disrupt what and how it is being shared.

Strategically, Uber responded to changes in social concerns from a financial standpoint by offering an economy (cheaper) and business (luxury) class transportation for any destination that a customer chooses. Uber also offered a large 8 seats vehicle for group transportation in an attempt to tap into group vehicle sharing sector (Yao et al., 2017).

To further shore up how further issues can emerge as the business model gets scoped using various strategic tools, scoping it with Porter (1979) porters five forces framework presents its own set of unique concerns like competition, buyer power, supplier power, etc. The works of Castillo et al. (2018) resonates with this as it reviewed how some leading firms (like Airbnb and HomeAway) balanced the power possessed by the product sharers and the seekers. In turn, more sharers meant more choices for the seekers as well as ensured that the users' subscription and geographical coverage increased to ensure that spare items were not kept idle for too long. In fact, it is currently possible for a would-be idle accommodation to be shared ahead of its availability time on the website and mobile apps of Airbnb and HomeAway.

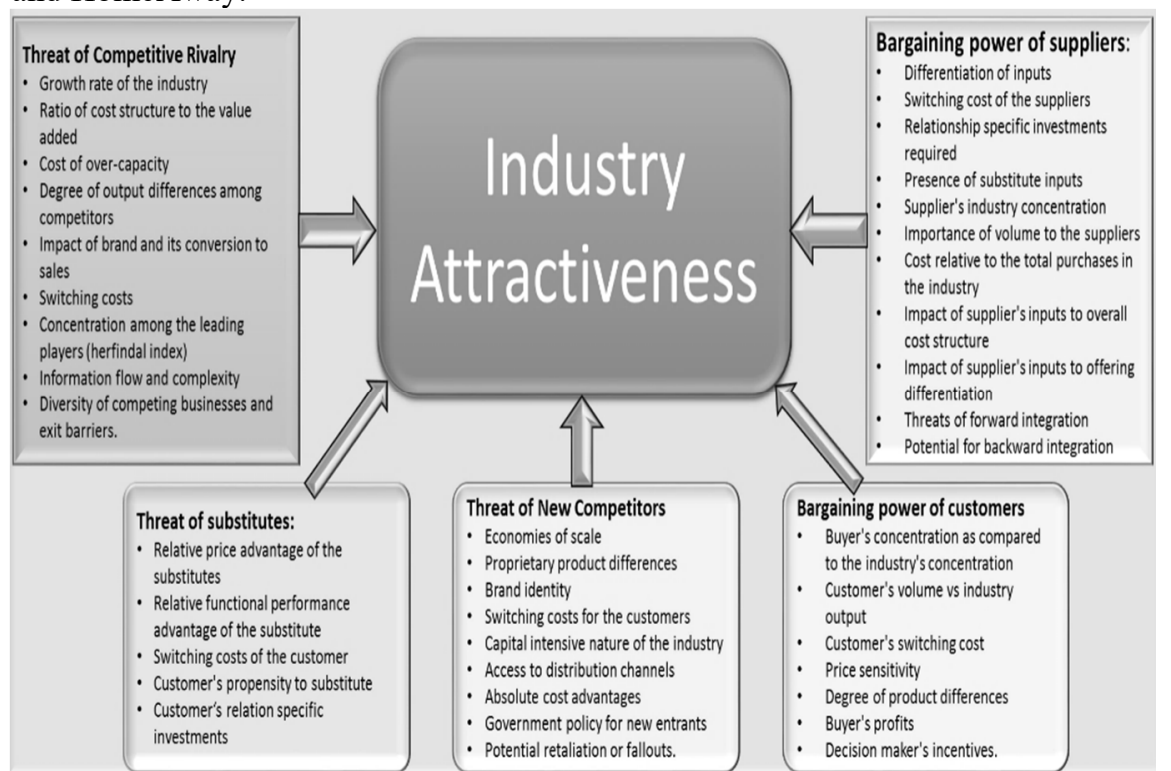

Figure 2.2: Porters' five forces within 1 Porters' five forces within the sharing economy.

Also, the mechanisms of the market can be a source of encouragement for the elasticity of pricing, thus moving towards advanced levels of buyer-to-seller matching or buyer-to-service matching in the case of services. Buyers can profit from an increased competition between the sellers from the perspective of pricing, quality and choice. This is now a common practice in the holiday accommodation sector of the sharing economy (Kathan, 2016).

There exist social benefits that can be derived from the participation of peers in the sharing economy. Benefits like increase in resource sustainability by allocating them more efficiently could reduce the environmental damage that would have been caused by production. However, questions as to how this remains a benefit continues to be widely argued in most discus that tends to tilt towards the disruptions caused by sharing economy (Fraiberger and Sundararajan, 2017). Although, for vehicle share sectors, such benefits can almost resonate with the majority that seeks fewer vehicles and lesser emissions on the road. Along this line, leading firms like Uber used very advanced global positioning systems (GPS) to enable their driver to complete their tasks whilst making less use of low emission zones as well as less fuel (Dillahunt and Malone, 2015).

Whilst much remains to be explored and reviewed about various approaches deployed by leading organisations that use technology to enhance sharing within the sharing economy, it is worth noting that according to Carr (2003) technology is the vehicle and strategy is the driver towards the corporate goals desired by leading firms. The notable empirical evidence below is offered to reinforce the benefits derived from applying technology to strategy within the sharing economy in. 


\section{Transportation}

Just in Stockholm, Uber impacts is said to help consumers benefit from less traffic, congestion and lower fares (Puschmann and Alt, 2016).

\section{Accommodation}

Between the year 2012 - 2013, Airbnb hosts hosted over 224,000 guests which totalled $£ 170 \mathrm{~m}$ and created 1100 jobs both part-time of full-time (Zervas et al., 2017).

Financial services

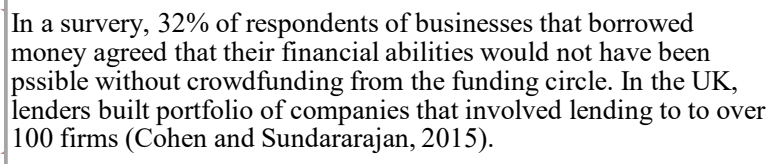

Figure 2.3: Some empirical evidence of success within the sharing economy.

\section{Criticisms and the Continuous Quest for Stringent Regulations}

Despite the benefits of sharing properties using technology in the sharing economy, Malhotra and Van Alstyne (2014) noted that numerous countries (especially in Europe) have raised concerns regarding licensing, taxation, quality compliance, insurance, health and safety and employee safeguarding. A typical example involves complaints relating to lack of food hygiene and health and safety measures in accommodations shared via Airbnb. Another involves the circumvention of insurance obligations for Uber taxis. Questions as to whether businesses that share through technology should be regulated continues to remain a worthwhile debate among governments and authorities. Alternatively, Rauch and Schleicher (2015) reckons that the entry barrier and operation requirements for firms that enhance sharing via technology platform should be concurrent to those faced in a traditional market; in other words, level the playing field. This line of thought remains susceptible to the argument of Fitzmaurice et al. (2016) which contended that businesses in technological model cannot be reduced to the same traditional regulations. Fitzmaurice et al. (2016) maintained that sharing on technology platform would need its own set of regulations that would enable it to continue to evolve and support the economy as opposed to restraining its growth using 'unnecessary regulations'. Because Fitzmaurice et al. (2016) failed to contextualise what the term 'unnecessary regulations' connotes in all its entirety, this opens up further arguments about existing regulations that governs sharing in the traditional (non-technological enhanced) model.

This narrative is no different from those that underpins the advantages of regulations in other settings; Schneider (2017) noted that regulations should be introduced to better the outcome that market structures would have yielded or to address failures where market structures could not. A typical example would involve lack of sufficient information to describe the quality of properties or services being exchanged in a transaction. Such situation would lead to market failure due to the asymmetry of information between those involved. In such instance, regulations such as adherence to quality standards and health and safety would be imperative to address such market failures. In the case of Uber in London, the transport authority, Transport for London (TFL) requires Uber drivers to have taxi licenses that involves drivers attaining a certain navigation skills. Airbnb also operates along the health and safety regulations with critics urging the government to impose a regulation on Airbnb that would imply that all hosts are vetted prior to listing their properties.

Although, the works of Falcone (2017) points out that in numerous industries, especially those where businesses that provide technological sharing platform have succeeded, there exist arguments that the use of technology is providing a panacea of opportunities for leading innovations than the incumbent market structure did. For example, the review and rating systems (like Trip Advisor) are seen as an act of peer quality assurance on the product and services and an avenue for reward to well-behaved sellers and buyers. In this instance, technology is used as a catalyst for indirect market-focused regulations. This act can undermine the need for the existence of historical regulations.

\section{Some Pertinent Disruptions Within the Sharing Economy}

There are some perceived disruptions caused by firms that innovate with technology within the sharing economy, some of them are outlined as follows. 
4.1 Unfair Competition: Technology-Enhanced Sharing Makes Searching and Matching Easy

The use of advanced search algorithms by mobile apps and websites to enhance the matching of seekers with the right properties makes it difficult for traditional market players to compete using traditional intermediaries. (Koopman et al., 2014).

\subsection{Lower Entry Barrier: Sharing Via Technology Reduces Entry Barrier and Increases Competition}

There tends to be low costs associated to entering and operating within a technology enhanced sharing market. This impacts existing traditional firms by giving infant firms the ability to compete in the market and forcing existing traditional firms to give up their market shares and exit the market (Fradkin et al., 2015).

\subsection{Regulations: Technology-Enhanced Sharing Introduces Incongruences in Regulations}

Existing traditional firms argue that there are incongruences in the regulations that governs them and those that governs businesses in the sharing economy. Although, advocates of technology enhanced sharing argue that the incongruence is significant in demonstrating the disparity between the business models and that imposing regulations would have a negative impact on consumer benefits (Nosko and Tadelis, 2015).

\subsection{Quality Standards: Sharing Via Technology Undermines the Traditional Quality Procedures}

The inaccuracy of reviews, ratings and feedbacks has been perceived as prejudice quality assurance process. Critics claim that it is besieged by numerous factors like the level of skills, language, bias, geography, just to mention a few. Buyers tend to take the word of mouth that a property or service is up to the required standard and worthy of the fee requested. The reliability of this notion can be a huge disruption to the traditional quality assurance procedures (Falcone and Imbert 2017).

\subsection{Financial Risk Factors: Technology-Enhanced Sharing Introduces More Financial Risks}

In the financial sector, quality is dependent on the degree of risks. Historically, insurance firms and banks simplified transactions in the traditional model. However, the perceived disruption is that technology in financial sharing economic platforms is attempting to replace existing financial intermediaries with an increased risk of fraud or giving credit to non-credit worthy participants (Schneider, 2017).

Despite the disruptions highlighted above, it is still hugely contested that sharing via technology platforms does not replace or phase out existing methods of sharing or firms that compete in the same market. Bratianu (2018) argued that products and services shared in the sharing economy are not substitutes to products and services that exist in the traditional marketplace (see Figure 4.2.). There is also another widely contested notion associated to holding but not having the properties shared. Wang (2018) elaborated how an increased sense of ownership can make an impact on how a property is shared and the sustainability of the shared property.

Market Shares of Sharing Economy versus Traditional Platforms
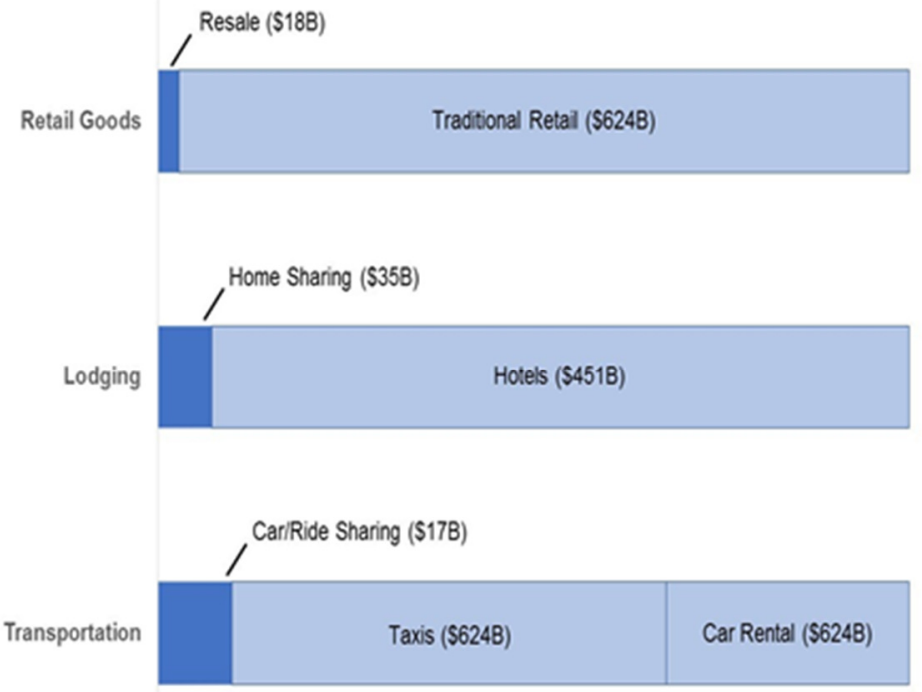

Source: Bank of
America, 2017

igure 4.1: Market Shares of Sharing Economy versus Traditional Platforms 


\section{Conclusion, Recommendations and Further Research Pathways}

Conclusively, based on the literature reviewed so far, it would appear that there is a continuous increasing scale of the firms and activities that emerges within the sharing economy, globally. Whilst this continuous growth presents a panacea of opportunities for growth and development from an economic standpoint, there are emerging concerns that needs to be studied, understood and addressed towards making this development an embraced global initiative. Although much remains to be explored, there are sufficient evidences from the studies of (Möhlmann (2015), Kathan (2016), Fraiberger and Sundararajan (2017), Dillahunt and Malone (2015), Puschmann and Alt (2016), Zervas et al. (2017), Cohen and Sundararajan (2015) to believe that there are disruptions that needs to be addressed towards stabilising market and encouraging steady market growth from continuous participation by firms.

Progressively, a recommendation is put forward that governments and authorities in various countries could attempt reviewing regulations to ensure that it fosters the growth of firms in the sharing economy as opposed to cripple them. If possible, governments and authorities in various countries could attempt supporting or subsidising traditional firms in order to help them survive the changing landscape of the market introduced by firms that share using technology.

From a scholarly standpoint, future researches could emerge from this study towards enhancing the body of knowledge. One study that could emerge can attempt exploring the views, attitudes and opinions of users of the sharing platforms regarding the regulations imposed by the government. However, such study would need to be followed up by a future study that would evaluate the impact of regulations on the users using methods other than narrative inquiries. It is envisaged that this study would be built upon during this program.

\section{References}

Bratianu, C. (2018) The crazy new world of the sharing economy. In Knowledge Management in the Sharing Economy (pp. 3-18). Springer, Cham.

Castillo, V. E., Mollenkopf, D. A., Bell, J. E., \& Bozdogan, H. (2018) Supply Chain Integrity: A Key to Sustainable Supply Chain Management. Journal of Business Logistics, 39(1), 38-56.

Cohen, M., \& Sundararajan, A. (2015) Self-regulation and innovation in the peer-to-peer sharing economy. U. Chi. L. Rev. Dialogue, 82, 116.

Cusumano, M. A. (2015) How traditional firms must compete in the sharing economy. Communications of the ACM, 58(1), 32-34.

Dillahunt, T. R., \& Malone, A. R. (2015) The promise of the sharing economy among disadvantaged communities. In Proceedings of the 33rd Annual ACM Conference on Human Factors in Computing Systems (pp. 22852294). ACM.

Carr, N. G. (2003). IT doesn't matter. Educause Review, 38, 24-38.

Dyal-Chand, R. (2015) Regulating Sharing: The Sharing Economy as an Alternative Capatilist System. Tul. L. Rev., 90, 241.

Falcone, P. M., \& Imbert, E. (2017) Bringing a sharing economy approach into the food sector: The potential of food sharing for reducing food waste. In Food Waste Reduction and Valorisation (pp. 197-214). Springer, Cham.

Fitzmaurice, C. J., Ladegaard, I., Attwood-Charles, W., Cansoy, M., Carfagna, L. B., Schor, J. B., \& Wengronowitz, R. (2016) Domesticating the market: moral exchange and the sharing economy. SocioEconomic Review.

Fradkin, A., Grewal, E., Holtz, D. and Pearson, M. (2015) Bias and reciprocity in online reviews: evidence from field experiments on Airbnb. The Sixteenth ACM Conference on Economics and Computation.

Fraiberger, S. P., \& Sundararajan, A. (2017) Peer-to-peer rental markets in the sharing economy.

Kathan, W., Matzler, K., \& Veider, V. (2016) The sharing economy: Your business model's friend or foe?. Business Horizons, 59(6), 663-672.

Koopman, C., Mitchell, M., \& Thierer, A. (2014) The sharing economy and consumer protection regulation: The case for policy change. J. Bus. Entrepreneurship \& L., 8, 529.

Lewin, K. (1943) Defining the 'Field at a Given Time. Psychological Review. 50(3): 292-310. Republished in Resolving Social Conflicts \& Field Theory in Social Science. Washington, D.C.: American Psychological Association, 1997.

Lou, L., \& Koh, J. (2018) Factors Affecting User Participation in Sharing Economy: The Case of Commercial Bike Sharing Service in China.

Malhotra, A., \& Van Alstyne, M. (2014) The dark side of the sharing economy... and how to lighten it. Communications of the ACM, 57(11), 24-27.

Martin, C. J. (2016) The sharing economy: A pathway to sustainability or a nightmarish form of neoliberal capitalism?. Ecological economics, 121, 149-159.

Matzler, K., Veider, V., \& Kathan, W. (2015) Adapting to the sharing economy. MIT.

Möhlmann, M. (2015) Collaborative consumption: determinants of satisfaction and the likelihood of using a 
sharing economy option again. Journal of Consumer Behaviour, 14(3), 193-207.

Nosko, C. and Tadelis, S. (2015) The Limits of Reputation in Platform Markets: An Empirical Analysis and Field Experiment. NBER Working Paper No. 20830.

Porter, M.E. (1979) How Competitive Forces Shape Strategy, Harvard Business Review.

Puschmann, T., \& Alt, R. (2016) Sharing economy. Business \& Information Systems Engineering, 58(1), 93-99.

Quattrone, G. Proserpio, D., Quercia, D., Capra, L., \& Musolesi, M., (2016, April) Who benefits from the sharing economy of Airbnb?. In Proceedings of the 25th international conference on World Wide Web (pp. 13851394). International World Wide Web Conferences Steering Committee.

Rauch, D. E., \& Schleicher, D. (2015) Like Uber, but for local government law: the future of local regulation of the sharing economy. Ohio St. LJ, 76, 901.

Schneider, H. (2017) Creative Destruction and the Sharing Economy: Uber as Disruptive Innovation. Edward Elgar Publishing.

Sundararajan, A. (2016) The sharing economy: The end of employment and the rise of crowd-based capitalism. Mit Press.

Wang, W. (2018) The differentially associated sharing economy. New Media \& Society, 1461444818769572.

Yao, Z., \& Zhu, C. (2017) Pricing Strategy of Sharing Economy with Cross-Group Network Effect.

Zervas, G., Proserpio, D., \& Byers, J. W. (2017) The rise of the sharing economy: Estimating the impact of Airbnb on the hotel industry. Journal of Marketing Research, 54(5), 687-705.

Anietie Ukpabio, BSc (Hons), MSc, MBA, Cert Ed, MABE, MBCS, QTLS, FHEA I am a PhD Researcher at Lancaster University and a certified Business Analyst at IBM Client Innovation Centre.

My major interest posits in conducting research into the connections between our material surroundings, the technologies (beyond computers) that permeate them, and the ways we act, think and learn. Two recurring interests are how institutions design and evaluate their built environment domain to support opportunities for learning. More general interests include Activity Theory, networked and collaborative learning. Additionally, I also am concerned with collaborative work and group discussion in digitally-mediated environments, with a theoretical and practical commitment to social justice and equity within learning communities. I am interested in understanding the ways that sociocultural and sociotechnical elements inherent in applications of digital education operate to marginalise students who fall outside the ideations of dominant ideology.

Apart from my previous software and IT industry experience, I am also a qualified teacher and my previous teaching background involves being a former Computing Lecturer at East Kent College, New Vic College and City College Norwich.

My major qualifications are a first class honours degree in Computing from the University of Greenwich, an MSc. distinction in Information Technology from the Cardiff Metropolitan University, an MBA from University of Northampton. 